\title{
Magnitude and factors for method discontinuation and switching among long acting reversible contraceptive users in health facilities of Southern Ethiopia
}

\author{
Tessema Bereku ${ }^{1 * \dagger} \mathbb{D}$, Yitagesu Habtu ${ }^{2,6 \dagger}$, Bereket Abreham ${ }^{3 \dagger}$, Menen Ayele ${ }^{4}$ and Melesech Eliso ${ }^{5}$
}

\begin{abstract}
Background: Long Acting Reversible Contraceptives (LARCs) are contraceptives that prevent unplanned pregnancy in a more safer and effective way than other modern short acting methods. However, method discontinuation and switching are still challenges for utilization of LARCs in resource limited countries for several reasons. Thus, the aim of this study was to determine magnitude and factors for method discontinuation and switching among LARCs users in health facilities of Southern Ethiopia.
\end{abstract}

Methods: A Facility based record review was used to collect data from May to June 2019. Three hospitals were randomly selected from five hospitals found in southern Ethiopia. A total of 1050 records were included in the study from long acting family planning registers between 2018 and 2019. Data were entered to Epi-info 3.5.4 and exported to SPSS for windows version 20 for analysis. A descriptive statistics was performed to describe factors and reasons for LARCs discontinuation and switching off. Logistic regression technique with a 95\% confidence level was used to determine the association between factors and magnitude of method discontinuation and switching.

Results: Of the 1050, $69.8 \%$ of women discontinued long acting reversible family planning method before the recommended duration of use and $30.2 \%$ of them switched from long acting family planning methods to any other modern contraceptive methods. Women who shifted from any LARCs to short-acting family planning methods accounted for $38.8 \%$ of those who shifted to any other modern methods. Desire to get pregnant and method specific side effect were most common reasons for both method discontinuation and switching. Women with only one child were 1.61 times more likely to discontinue than women who had greater than five number of children.

Conclusion: Discontinuation and switching of long acting reversible family planning method was high. Primiparous women were more likely to discontinue use of long acting reversible family planning methods. Re-evaluating family planning services focusing on effective counseling about side effects of LARCs methods is required. Training should also be given for family planning providers including community healthcare workers.

Keywords: LARCs, Discontinuation, Switching, Primiparous

\footnotetext{
*Correspondence: t.bereku@yahoo.com

${ }^{\dagger}$ Tessema Bereku, Yitagesu Habtu and Bereket Abreham equally contributed to this work

1 Department of Midwifery, Hossana College of Health Sciences, P.O. Box:

159, Hossana, Ethiopia

Full list of author information is available at the end of the article
}

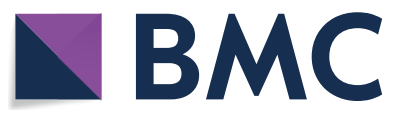

(c) The Author(s) 2022. Open Access This article is licensed under a Creative Commons Attribution 4.0 International License, which permits use, sharing, adaptation, distribution and reproduction in any medium or format, as long as you give appropriate credit to the original author(s) and the source, provide a link to the Creative Commons licence, and indicate if changes were made. The images or other third party material in this article are included in the article's Creative Commons licence, unless indicated otherwise in a credit line to the material. If material is not included in the article's Creative Commons licence and your intended use is not permitted by statutory regulation or exceeds the permitted use, you will need to obtain permission directly from the copyright holder. To view a copy of this licence, visit http://creativecommons.org/licenses/by/4.0/. The Creative Commons Public Domain Dedication waiver (http://creativeco mmons.org/publicdomain/zero/1.0/) applies to the data made available in this article, unless otherwise stated in a credit line to the data. 


\section{Plain language summary}

Ethiopia has a substantially greater percentage of unintended pregnancy than other developing and developed countries. Long-acting reversible contraception (LARC) has a potential to address a huge and growing unmet need in resource limited countries like Ethiopia, such as reducing unwanted births and abortion rates.

As part of this global approach to fertility management, Ethiopia has been implementing various strategies like an on-going task shifting and task sharing with the implanon scale up program, and IUD revitalization program starting from the community health services to higher level healthcare systems to increase access and utilization of long acting reversible family planning methods. However, discontinuing LARCs before the recommended duration use and switching to short-acting contraceptives have proven difficulty in Ethiopia. This may have led to low utilization rate of LARCs in Ethiopian contexts including the study area, when compared to the national target. Very low coverage of use of LARC among unmet need has shown by many studies in various corners of the country. Thus, determining the magnitude and factors of LARC discontinuing and switching is still a pressing need to establish additional strategies used to improve consistent use of LARC for the recommended duration and expand access to LARC for better planning of births.

In this study we assessed magnitude and factors of LARC discontinuation and switching from a relatively huge number of records extracted from systematically selected health facilities in Southern Ethiopia. Extracted data from registers of long acting reversible family planning methods were analysed using descriptive statistics and logistic regression. Accordingly, we found significant proportion women discontinued long acting reversible family planning methods before the recommended duration of use as well as switched from long acting reversible family planning methods to other modern short-acting methods due to various reasons. Only a number of children women had is associated with discontinuation and no single factor was associated with method switching in Southern Ethiopia. Family planning services should be re-evaluated with a focus on effective counseling on the side effects of LARCS approaches, and training for family planning providers, particularly community healthcare workers, should be provided.

\section{Background}

Family planning is one of the most cost effective health promotion programs reducing maternal and child mortality by roughly $30 \%$ and $10 \%$, respectively [1]. Despite significant reduction of maternal and child mortality due to fertility related causes from 1990, the burden of both maternal and child mortality high in low resource setting countries Approximately 295,000 maternal deaths occurred globally in 2017 and 94\% of which was from low resource countries. Sub-Saharan Africa and South Asia accounted for $86 \%(254,000)$ of global maternal deaths in 2017 [2]. Similarly, 5.4 million children died in 2017 globally and $89 \%$ of them are from low and middle income countries. Fortunately, the vast majority of maternal and child deaths can be prevented with proven interventions including effective birth control using modern contraceptions mainly LARCs [3].

Worldwide contraceptive utilization has increased during the last 10 years [4]. Unfortunately, many other regions of the developing world including Africa still have a high unmet need for family planning. In subSaharan Africa, an estimated $25 \%$ of women and couples who want to space or limit their births are not using any form of contraception. Because more than half of Africa's population is under the age of 25 , unmet need for family planning is likely to rise as these individuals enter their reproductive years [5].

Long-acting reversible contraceptives (LARCs) are contraceptive methods that prevent unplanned pregnancy for a long period of time without the need to any further responsibility by the user. They include the Intrauterine Contraceptive Devices (IUCD), Implants and Jadelle [6, 7]. Such modern contraceptives are more effective and cost-effective methods that play a role in reaching the national and international birth control goals.

The government of Ethiopia, national fertility rate of 4.6 children per women with a $2.7 \%$ per year population growth rate [8] has targeted $55 \%$ contraceptive prevalence rate by the year 2020 . Of which, $35 \%$ is targeted for LARCs [9] implying that much needs to be done to catalyze the uptake of these methods. Despite this target, the utilization coverage of LARCs remains small sometimes missed component of many national reproductive health and family planning programs [5]. In light of this, the country has implemented different strategies such as task shifting to enhance the utilization coverage of LARCs at the primary healthcare level in all regions, including the southern region.

Method discontinuation and switch off are challenges for underutilization of most effective modern contraceptives, LARCs in limited resource settings 
for several reasons [10, 11]. Method discontinuation in this study refers to stopping use of specific LARCs within the recommended duration and discontinuing the previous method and switching to another LARCs [12]. Desire to conceive, unexpected conception, and side effect or health concern were the most prevalent reasons reported for discontinuing contraceptive methods, regardless of the method currently in use [11]. Method shift (switch off) from LARCs [13] to any other short-acting methods mainly due to poor competency of providers in counseling, providers' gender, providers' position and sector, provider myths is one of the reasons for inconsistent use of LARCs [13].

In low income countries including Ethiopia, the proportion of family planning users who switch off from reversible long acting family planning methods to less effective methods reaches up to 40.4\% [13]. According to the 2016 Ethiopian Demographic Health Survey (EDHS), percentage of long acting reversible contraceptive method episodes discontinued within 12 months were IUCD (13\%) followed by implants (11\%) among women age 15-49 [14].

Southern nation's nationalities and people's regional health bureau of Ethiopia set a strategic plan to achieve the coverage of long acting reversible family planning users from 24 to $60 \%$ according to the Health Sector Transformation Plan (HSTP) in 2020 [9]. However, the utilization coverage of the long acting reversible family planning is significantly lower than the expected coverage due to various reasons. Discontinuation from using and switching from long acting reversible family planning methods to short acting methods might contribute to low utilization of long acting reversible family planning methods. The reasons for discontinuation and switching might be highly contextual depending on cultural variations and time elapse. Method discontinuation and switching from long acting family planning to short acting modern or traditional methods leads to the risk of unplanned pregnancy [15] that may expose for unsafe abortion [16] and Sexually transmitted infections (STIs)/ Human immunodeficiency virus (HIV) infection [17]. However, information regarding methods discontinuation from using long acting reversible family planning methods and shift from highly effective method to less effective methods is largely unknown in the study area. Therefore, the aim of this study was to determine the magnitude of discontinuation and switching, and reasons for method discontinuation and switching off long acting reversible contraceptives.

\section{Methods}

\section{Study setting}

The study was done in three randomely selected hospitals found in central Southern Ethiopia, Hadiya Zone. There were five hospitals providing family planning services including LARCs during data collection period. The hospitals include Wachamo University Nigist Eleni Mohamed Memorial referral Hospital (WUNEMMRH), Shone Primary Hospital, Gimbichu Primary Hospital, Homecho primary hospital and Bonesha primary hospital. All hospitals have been providing family planning services since family planning program and strategies began to be implemented. According to the national health information system of the country, all healthcare facilities are expected to register LARCs users using a separate standard registration book since 2018. IUCD, implants (Implanon, and Jadellele) are available LARCs in all family planning services in Southern Ethiopia including the study area. There were more than 1200 long acting family planning users every year in the catchment area according to 2018 report of the Zone. The coverage of long acting reversible family planning service utilization was reported to be low; ranging from 15 to $20 \%$ among the eligible women in 2018 according to reports of Zonal Health Bureau [18].

\section{Study design and period}

A facility based record review was used to assess magnitude, reasons and factors of discontinuation and switching among long acting reversible family planning (LARCs) users in public health facilities in Hadiya Zone in Central Southern Ethiopia from May to June 2019.

\section{Study participants and sampling}

Data are extracted from records of long acting reversible family planning users who revisit the hospital family planning unit. A total of 1050 records in long acting family planning registers from 2018 to 2019 were included in the study from three randomly selected hospitals found in Hadiya Zone. The records from 2018 to 2019 were used because of healthcare facilities had started using a standard LARCs registration book since 2018-2019, the end of the study period. For the record review, three hospitals were chosen at random from a list of five hospitals as sampling frame in zonal health bureaus, assuming that the LARCs users have little variation in contextual factors with regard to socio-demographic and other characteristics. In addition, all hospitals have been fully providing long acting reversible family planning services and started to use a standard LARCs registration book. 


\section{Study variables}

The dependent variables of the study were discontinuation of long acting reversible family planning methods and switching off from long acting reversible family planning to any other modern methods. Method discontinuation for this study refers to when the woman stop using a previously chosen specific LARC within the recommended duration of use. Method switching for this study refers to the case where a woman made shifts from currently using a specific LARCs to other specific LARC, or other specific modern contraceptives. LARCs for this study applies to available modern contraceptives across all family planning services of healthcare facilities in the study area such as implants (implanon and Jadellele) and IUCD.

Whereas, the independent variables include sociodemographic characteristics of users, types of family planning methods previously used, and HIV testing status. Socio-demographic variables include age, marital status, education, place of residence, parity, and gravidity.

\section{Data collection and measurement}

A checklist with similar data items of the standard LARCs registries and women card was prepared to collect the relevant information about the users who revisit family planning unit. For more clarity, see the English version checklist (Additional file 1: Annex 1). Sociodemographic and related data that were not available in the standard LARCs registries were extracted from the women cards. Long acting reversible family planning users who came to discontinue the LARC which has been in use and came to switch to other methods for any reasons were extracted to determine the magnitude of discontinuation and switching.

Records available before 2018 were excluded because all five hospitals were not equally using a standard national LARCs registries. I Similarly, incomplete records were excluded from analysis. The data collectors and supervisors were trained how to extract the data using the checklists that had been prepared. The supervisors monitored the data collection process regularly on a daily basis. Daily checkup was made to ensure completeness and consistency of the data in the checklists.

\section{Data processing and analysis}

Data recorded on the checklists were entered to Epi-info 3.5.4 after checking consistency and completeness. Then, the data were exported to SPSS for windows version 20 for performing statistical analysis.

A descriptive statistics was performed to describe factors and reasons for LARC discontinuation and switching off. The variables were described using a variety of frequency tables, charts, and summary measures.
Proportion was used to determine magnitude of both outcome variables (discontinuation and Switching off LARCs) separately.

Logistic regression with standard entry method was used to determine the association between socio-demographic variables and magnitude of discontinuation; socio-demographic variables and switching off LARCs. We computed odds ratio with $95 \%$ confidence interval to show the strength of the association between independent variables and dependent variables (magnitude of discontinuation and switching off). Bivariate logistic regression with standard method was used to see the crude association between independent variables and magnitude of discontinuation. We used a similar step to determine the crude association between independent variables and magnitude of switching off LARCs. Despite we planned to take variables having statistically significant results (P-value $<0.05)$ to the multiple logistic regression, there was only one eligible variable (number of children the women have) with both magnitude of discontinuation so that the result obtained in bivariate logistic regression model was taken as independent factor for discontinuation of LARCs. We used a similar step in the case of switching off LARCs however there was no single variable associated with switching off LARCs in a bivariate logistic regression.

\section{Results}

\section{Socio-demographic characteristics of women}

A total of 1050 women were included in the analysis. The median age of the women was about 28 years and the minimum age was 15 while the maximum age was 45 . Majority of women were younger than 35 years old and while only $2.2 \%$ were in the later adolescent age category. Nearly one in ten women had not received formal education whereas more than half of the women had attained primary and secondary level education. The number of children who had ever born from the women was ranged from 0 to 7 while the number of times that a woman had been pregnant ranged from 0 to 8 . A vast majority of the women, $96.1 \%$, had married. More than half of the women, $55.8 \%$, resided at rural area. The distribution of socio-demographic characteristics is depicted in Table 1.

\section{Discontinuation and switching of LARCs methods}

Of the 1050 users of LARCs, the methods chosen were implanon, IUCD and Jadelle in the period before removal. Implanon was the most common long acting reversible family planning method used by 871 (83\%) women followed by intrauterine contraceptive device (IUCD) 91 (8.7\%), and Jadelle 88 (8.4\%).

Seven hundred and thirty three (69.8\%) of women discontinued the specific LARC within 1 year of 
Table 1 Distribution of socio-demographic characteristics of women of long acting family planning users, Hadiya Zone, Ethiopia, 2019

\begin{tabular}{|c|c|c|}
\hline Variables & Frequency & Percent \\
\hline \multicolumn{3}{|c|}{ Women's age at times of removal of LARCs } \\
\hline $15-24$ & 222 & 21.1 \\
\hline $25-34$ & 680 & 64.8 \\
\hline 35 or More & 148 & 14.1 \\
\hline \multicolumn{3}{|l|}{ Education } \\
\hline Illiterate & 102 & 9.7 \\
\hline Primary education & 281 & 26.8 \\
\hline Second education & 294 & 28.0 \\
\hline College or above & 373 & 35.5 \\
\hline \multicolumn{3}{|l|}{ Place of residence } \\
\hline Rural & 586 & 55.8 \\
\hline Urban & 464 & 44.2 \\
\hline \multicolumn{3}{|l|}{ Marital status } \\
\hline Single & 12 & 1.1 \\
\hline Married & 1009 & 96.1 \\
\hline Divorced & 17 & 1.6 \\
\hline Widowed & 12 & 1.1 \\
\hline \multicolumn{3}{|l|}{ Number of living children } \\
\hline No child & 25 & 2.4 \\
\hline One child & 225 & 21.4 \\
\hline Two to four child & 577 & 55.0 \\
\hline Five or more child & 223 & 21.2 \\
\hline \multicolumn{3}{|l|}{ Total pregnancy } \\
\hline No pregnancy & 4 & 0.4 \\
\hline One pregnancy & 383 & 16.2 \\
\hline Two to four pregnancy & 477 & 51.8 \\
\hline Five or more pregnancy & 186 & 31.6 \\
\hline
\end{tabular}

insertion without shifting to any other modern contraception. Whereas 317 (30.2\%) of women switched from long acting family planning methods to any other modern contraceptive methods. Of the 317 women, $123(38.8 \%)$ of them were switched from the long acting reversible contraceptives to short acting modern family planning methods whereas 194 (61.2\%) of them were shifted from one specific LARC to another LARC.

The mean duration of use for all long acting reversible family planning methods was $19.3 \pm 15.2$ months. The mean durations of use for Implanon, IUCD and Jadelle were $19.3 \pm 12.2,24.4 \pm 26.8$ and $31.8 \pm 22.2$ months, respectively. Table 2 presents all-method and methodspecific duration of use among women who discontinued a specific method. One hundred twenty two (16.6\%) of women discontinued for all methods after 6 months protection of unintended pregnancy and increased to $40.4 \%$ after more than 24 months protection of unintended pregnancy. Implanon had the lowest 6 month discontinuation rate $(15.4 \%)$ followed by Jadelle (16.9\%). More than a quarter of women discontinued IUCD (28.8\%) within 6 months duration of use. The highest discontinuation rate is recorded for Jadelle (55.9\%) followed by IUCD (44.1\%) after 2 years of use.

Among those women who switched from the specific LARC, 256 (80.8\%) switched from implanon to other modern contraceptive methods. Of which, 107 (41.8\%) switched from implanon to other short acting methods (male condom, pills, injectables) and 149 (58.2\%) switched from implanon to other long acting reversible family planning methods (IUCD and Jadelle). Thirty two (10.1\%) switched from IUCD to other methods and 29 (9.2\%) switched from Jadelle to other methods (Table 3).

The women's initial long-acting reversible family planning method and destination method is depicted in Table 3. The majority of women who were using implanon 615 (58.6\%) stopped from using any modern contraceptive methods after removal. The three most modern contraceptives preferred by women after removal of Implanon were IUCD 96 (9.1\%), implant (Jadelle or implanon) 53 (5.0\%), and injectables 49 (4.7\%). Out of women who were using Jadelle, 59 (5.6\%) of them stopped from using the method. Whereas, 17 (1.6\%) of them shifted to implant (implanon or Jadelle).

\section{Reasons for discontinuation and switching off LARCs}

Of the total women who were using specific LARC, 440 (41.9\%) of them sought removal services due to method

Table 2 Percentage of women who discontinued a method at 6, 12, 18, 24, and more than 24 months duration of use of LARCs, by method, Hadiya Zone, Ethiopia 2019

\begin{tabular}{|c|c|c|c|c|c|c|}
\hline Method & $\begin{array}{l}6 \text { months } \\
\text { Number (\%) }\end{array}$ & $\begin{array}{l}12 \text { months } \\
\text { Number (\%) }\end{array}$ & $\begin{array}{l}18 \text { months } \\
\text { Number (\%) }\end{array}$ & $\begin{array}{l}24 \text { months } \\
\text { Number (\%) }\end{array}$ & $\begin{array}{l}\text { More than } 24 \text { months } \\
\text { Number (\%) }\end{array}$ & $\begin{array}{l}\text { Total } \\
\text { Number (\%) }\end{array}$ \\
\hline Implanon & 95 (15.4\%) & 115 (18.7\%) & 101 (16.4\%) & 67 (10.9\%) & 237 (38.5\%) & 615 (100.0\%) \\
\hline Jadelle & 10 (16.9\%) & $5(8.5 \%)$ & $9(15.3 \%)$ & $2(3.4 \%)$ & 33 (55.9\%) & 59 (100.0\%) \\
\hline IUCD & $17(28.8 \%)$ & $10(16.9 \%)$ & $3(5.1 \%)$ & $3(5.1 \%)$ & $26(44.1 \%)$ & 59 (100.0\%) \\
\hline Total & $122(16.6 \%)$ & 130 (17.7\%) & $113(15.4 \%)$ & $72(9.8 \%)$ & $296(40.4 \%)$ & 733 (100.0\%) \\
\hline
\end{tabular}


Table 3 Previously used long acting reversible family planning methods and post removal contraceptive family planning methods, Hadiya Zone, Ethiopia 2019

\begin{tabular}{lcllcccc}
\hline Method & $\begin{array}{l}\text { Male condom } \\
\text { Number (\%) }\end{array}$ & $\begin{array}{l}\text { Pills } \\
\text { Number (\%) }\end{array}$ & $\begin{array}{l}\text { Injectables } \\
\text { Number (\%) }\end{array}$ & $\begin{array}{l}\text { IUCD } \\
\text { Number (\%) }\end{array}$ & $\begin{array}{l}\text { Implant } \\
\text { Number (\%) }\end{array}$ & $\begin{array}{l}\text { No contraception } \\
\text { Number (\%) }\end{array}$ & $\begin{array}{l}\text { Total } \\
\text { Number (\%) }\end{array}$ \\
\hline Implanon & $10(1.0 \%)$ & $48(4.6 \%)$ & $49(4.7 \%)$ & $96(9.1 \%)$ & $53(5.0 \%)$ & $615(58.6 \%)$ & $871(83.0 \%)$ \\
Jadelle & $1(0.1 \%)$ & $0(0 \%)$ & $2(0.2 \%)$ & $9(0.9 \%)$ & $17(1.6 \%)$ & $59(5.6 \%)$ & $88(8.4 \%)$ \\
IUCD & $0(0.0 \%)$ & $6(0.6 \%)$ & $7(0.7) \%$ & $3(0.3 \%)$ & $16(1.5 \%)$ & $59(5.6 \%)$ & $91(8.7 \%)$ \\
Total & $11(1.0 \%)$ & $54(5.1 \%)$ & $58(5.5 \%)$ & $108(10.3 \%)$ & $86(8.2 \%)$ & $733(69.8 \%)$ & $1050(100.0 \%)$ \\
\hline
\end{tabular}

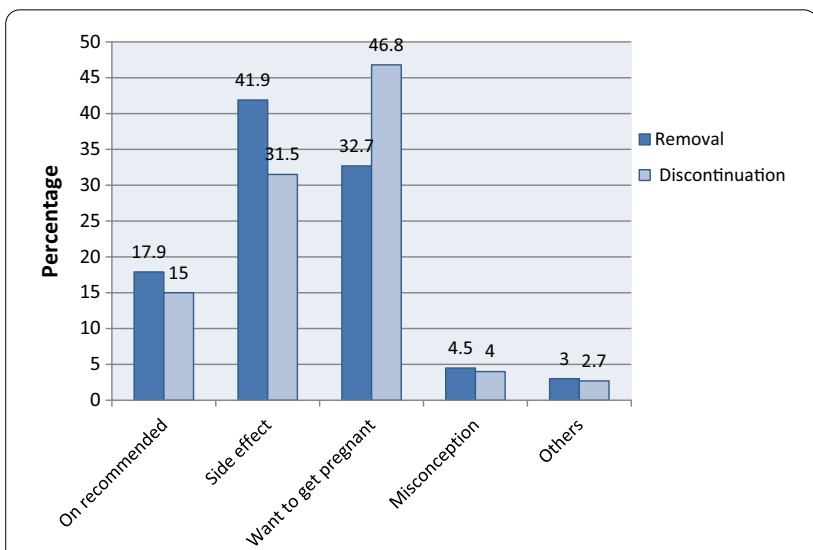

Fig. 1 Reasons for removal and discontinuation of long acting reversible family planning methods, Hadiya Zone, Ethiopia

specific side effects, followed by desire to get pregnant 343 (32.7\%). The two most common reasons for discontinuing a method were desire to become pregnant 343 (46.8\%) followed by method specific side effects 231 (31.5\%) among women who discontinued using it. Of women who discontinued the specific LARC, 390 (53.2\%) of them discontinued with reasons other than desire to become pregnant. Only 188 (17.9\%) of women sought removal services, and $110(15 \%)$ of those who discontinued specific LARC waited for the due date (the time when the effective date of the method was over). A few other women reported various reasons such as husband disapproval, marital dissolution, and so on (Fig. 1).

The two most important reasons given by the women who came for removal of implanon were side effects 359 (34.2\%) followed by desire to get pregnant 289 (27.5\%). Most common reasons reported by the women who were using Jadelle were side effect, 34 (3.2\%) followed by at due date of use 26 (2.5\%). Similarly, the commonest reasons provided by the IUCD users for removal were the side effects felt followed by desire to get pregnant (Table 4).

As shown on Fig. 2, among those women who switched from long acting reversible family planning to any method, the common reasons were side effect 209 (65.9\%) followed by due date of use of the method 78 (24.6\%).

\section{Factors affecting discontinuation and switching off LARCs}

Despite we planned to take variables having a P-Value less than 0.05 to the multiple logistic regression analysis, only number of children was significantly associated factors with discontinuation of long acting family planning methods in the bivariate analysis. Those women who had one living children were 1.61 times more likely to discontinue than women who had greater than five number of pregnancy [AOR: 1.61, 95\% CI: 1.61 $(1.07,2.42)$ ] (Table 5). In bivariate logistic regression, there was no single factor associated with switching off LARCs; hence no factors

Table 4 Reasons provided by the women who came to remove long acting reversible family methods by type of methods, Hadiya Zone, Ethiopia 2019

\begin{tabular}{lcccc}
\hline Reasons & $\begin{array}{l}\text { Implanon } \\
\text { Number (\%) }\end{array}$ & $\begin{array}{l}\text { Jadelle } \\
\text { Number (\%) }\end{array}$ & $\begin{array}{l}\text { IUCD } \\
\text { Number (\%) }\end{array}$ & $\begin{array}{l}\text { Total } \\
\text { Number (\%) }\end{array}$ \\
\hline On recommended & $158(15.0 \%)$ & $26(2.5 \%)$ & $4(0.4 \%)$ & $188(17.9 \%)$ \\
Side effect & $359(34.2 \%)$ & $34(3.2 \%)$ & $47(4.5 \%)$ & $440(41.9 \%)$ \\
Want to get pregnant & $289(27.5 \%)$ & $24(2.3 \%)$ & $30(2.9 \%)$ & $343(32.7 \%)$ \\
Misconception & $37(3.5 \%)$ & $1(0.1 \%)$ & $9(0.9 \%)$ & $47(4.5 \%)$ \\
Others & $28(2.7 \%)$ & $3(0.3 \%)$ & $91(0.1 \%)$ & $32(3.0 \%)$ \\
Total & $871(83.0 \%)$ & $88(8.4 \%)$ & $1050(100.0 \%)$ \\
\hline
\end{tabular}




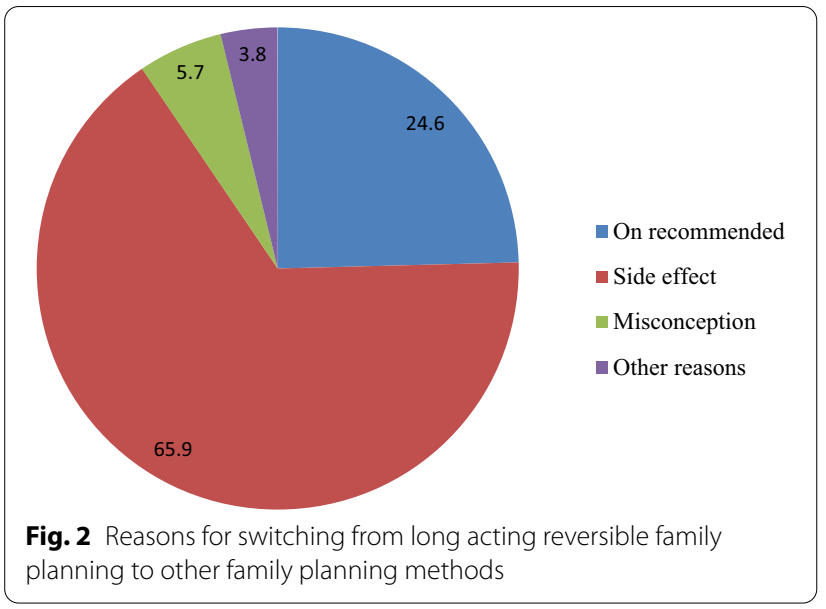

Fig. 2 Reasons for switching from long acting reversible family planning to other family planning methods were eligible for further multiple logistic regression analysis. Therefore, there was no statistically significant association between factors and switching off LARCs.

\section{Discussion}

Despite years had been counted since we had started implementing birth control through family planning methods, there is lower rate of utilization and early discontinuation and switching of long acting family planning methods that may expose women for unintended pregnancy. The present study determined the magnitude of early discontinuation and switching of common long acting modern family planning methods, reasons for discontinuation and factors associated with early discontinuation.

This study found that about seven in ten women discontinued any long acting reversible family planning method. This is by far higher than the findings from Honduras, where $41 \%$ of women discontinued using their first

Table 5 Factors associated with discontinuation of long acting reversible family planning in Hadiya zone, Ethiopia, June 2019

\begin{tabular}{|c|c|c|c|c|c|c|}
\hline Variable & Variable category & Frequency & Crude OR 95\% Cl & $P$ value & Adjusted OR 95\% Cl & $P$ value \\
\hline \multirow{3}{*}{$\begin{array}{l}\text { Women's age at times of } \\
\text { discontinuation }\end{array}$} & $15-24$ & 23 & 1 & & & \\
\hline & $25-34$ & 199 & $1.0(0.72,1.40)$ & 0.997 & & \\
\hline & 35 or more & 442 & $0.74(0.48,1.16)$ & 0.187 & & \\
\hline \multirow[t]{2}{*}{ Place of residence } & Rural & 586 & $0.84(0.63,1.09)$ & 0.173 & & \\
\hline & Urban & 464 & 1 & & & \\
\hline \multirow[t]{4}{*}{ Education of respondent* } & Illiterate & 102 & $0.96(0.60,1.53)$ & 0.849 & & \\
\hline & Primary education & 281 & $1.05(0.75,0.47)$ & 0.759 & & \\
\hline & Second education & 294 & $1.18(0.85,1.65)$ & 0.330 & & \\
\hline & College or above & 373 & 1 & & & \\
\hline \multirow[t]{4}{*}{ Marital status } & Single & 12 & 1 & & & \\
\hline & Married & 1009 & $1.66(0.52,5.29)$ & 0.388 & & \\
\hline & Divorced & 17 & $1.31(0.29,5.98)$ & 0.728 & & \\
\hline & Widowed & 12 & $2.14(0.38,12.20)$ & 0.390 & & \\
\hline \multirow[t]{4}{*}{ Number of living children } & No child & 25 & $0.71(0.31,1.64)$ & 0.426 & $0.71(0.31,1.64)$ & 0.426 \\
\hline & One child & 225 & $1.61(1.07,2.42)$ & 0.021 & $1.61(1.07,2.42)$ & 0.021 \\
\hline & Two to four child & 577 & $1.36(0.98,1.89)$ & 0.064 & $1.36(0.98,1.89)$ & 0.064 \\
\hline & Five or more child & 223 & 1 & & 1 & \\
\hline \multirow[t]{4}{*}{ Total number of pregnancy } & No pregnancy & 4 & $1.57(0.16,15.43)$ & 0.697 & & \\
\hline & One pregnancy & 383 & $1.37(0.94,1.99)$ & 0.100 & & \\
\hline & Two to four pregnancy & 477 & $1.19(0.83,1.70)$ & 0.345 & & \\
\hline & Five or more pregnancy & 186 & 1 & & & \\
\hline \multirow[t]{3}{*}{ Types of LARCs } & Implanon & 871 & 1 & & & \\
\hline & Jadelle & 88 & $0.85(0.53,1.35)$ & 0.486 & & \\
\hline & IUCD & 91 & $0.77(0.49,1.21)$ & 0.254 & & \\
\hline \multirow[t]{5}{*}{ Duration in months } & 6 or less & 173 & $0.95(0.65,1.41)$ & 0.812 & & \\
\hline & $6.1-12.00$ & 195 & $0.80(0.55,1.15)$ & 0.225 & & \\
\hline & $12.1-18.0$ & 168 & $0.82(0.56,1.21)$ & 0.311 & & \\
\hline & $18.1-24$ & 100 & $1.03(0.63,1.67)$ & 0.920 & & \\
\hline & 24.1 or more & 414 & 1 & & & \\
\hline
\end{tabular}


choice of LARC within 1-year follow up [19] and a Kenyan study, which found that the 12-month contraceptive discontinuation rate for all the methods was $30.5 \%$ and IUCD (6.4\%) followed by Implants (8\%), in 2014 [20]. In addition, it was higher than from the finding of the Ethiopian national health survey which indicated overall discontinuation rate of $35 \%$ for all the methods and method specific 1 year discontinuation of IUCD (13\%) followed by Implants (11\%) [14]. In fact, the findings of the EDHS may not be incomparable with this study due to the fact that the design of EDHS is population based whereas this study is facility based and among high risk group for discontinuation [14]

] Furthermore, the finding of the study was higher than the study from South East Ethiopia specifically for implanon [7] where $18.7 \%$ of women removed implanon within first year of use and (38.5\%) of women removed implanon after the second year of use. However, higher discontinuation rate is not necessarily at risk of unintended pregnancy due to the fact that desire to become pregnant is one of the most important reproductive rights of women..

The overall mean duration of LARCs use was four folds less than the recommended duration of use for the three LARCs analysed in this study. This finding could imply the risk of unintended pregnancy due to improper use of LARC methods. This finding has lower duration of use when compared to findings from other parts of Ethiopia $[21,22]$ and in UK [23] which ranged from 19.5 months to 27 months for implanon. In addition, the mean duration of LARC methods is lower than the findings from demographic health survey (DHS) of 14 developing countries where the mean duration of uninterrupted IUCD use was 37 months [24]. However, as to our knowledge there were no studies for Jadelle to compare mean duration of use. In any case of the above findings, our findings suggest that there might be the risk of improper use of LARC methods which in turn leads to unintended pregnancy. Therefore, the findings of study imply many efforts should be made to improve average duration of use of LARC methods to reduce the risk of unintended pregnancy.

Three in ten women in this study switched from the methods they were using to any other modern contraceptive methods. This is slightly higher than a study done in other parts of the country, Dilla (27.6\%) [25]. Here, as long as all methods are effective in preventing unintended pregnancy, the women may prefer to another method following discontinuation. But, switching from LARC methods to modern short-acting family planning methods may widen risk of unintended pregnancy and switching from one type of LARC to another type may also lead to risk of pregnancy. In our study, a significant number of women switched from previously used specific LARC methods to short acting family planning that may also expose them for unintended pregnancy. Our finding is higher than the findings from Bangladeshi (15.4\%) [13] and Senegal (17\%) [26]. Whereas, the findings of this study is lower than the finding reported in Ethiopia [5-7, 13]. Switching from LARC methods to other short-acting methods (less effective methods) might be due to failure to counselling, providers' gender factor, position and sector, provider myths that this finding call for implementing strategies to increase continuation rate of utilization of long acting family planning methods [6]. Moreover, higher proportion of Switching from one type of LARC methods to the other LARC methods might be another odd finding of this study, implying that the methods may have been improperly inserted. Hence, additional studies should be conducted regarding to competency of family planning providers so that their skill gap regarding insertion of LARC methods may be filled with additional training.

The two most cited reasons mentioned by the women for discontinuation of LARC methods in our study were desire to get pregnant and method specific side effect. Despite there is a difference in the design of the study, the findings of our study is consistent with findings extracted from the Ethiopian demographic health survey [22]. Similarly, reasons for implanon removal were similar with the study done in South Africa, which showed implanon was removed by the side effect and a desire for more pregnancies [27]. Moreover, side effect was also the main reason citedin the study done in Zambia (11\%) [28] and consistent with the findings from the African population and health research centre for East African [29].

In our logistic regression analysis, only number of living children of women was significantly associated with discontinuation of long acting reversible family planning methods. Although the design of the study varies, our finding is consistent with study done in Ethiopia [22]. However, in our finding primiparous women were more likely to discontinue when compared to the grand multipara women whereas a demographic health analysis indicated that higher number of living children is associated with discontinuation [22]. While other variables like age of women, duration of use of LARCs, and educational status were not associated with discontinuation in our findings. Similarly, there was no single variable associated with switching of LARC methods.

\section{Limitation and strength of the study}

Huge sample size of the study could be among the strengths of our study. In addition, the finding of our study may suggest poor quality of family planning services as is a facility based. Our study is a facility based 
that may result in higher estimation of discontinuation and switching off LARC methods than the survey design in the community due to high risk of removal of the method during revisit. This may unable to generalize to the general target groups in the community. Some of the most important variables that may have an association with discontinuation and switching off LARC methods are not available in the standard registration book. These variables could be confounders but we were unable to analyse.

\section{Conclusion and recommendation}

Our finding showed that discontinuation of long acting reversible family planning method was high. Method switching from long acting reversible family planning methods to short acting family planning methods was also high in our finding that may expose the women to unintended pregnancy. Desire to get pregnant and method specific side effect were most common reasons for both method discontinuation and method switching. In our study, primiparous women (those women having one living children) were more likely to discontinue use of long acting reversible family planning methods. Hence, re-evaluating family planning services focusing on how can effectively counsel side effects of corresponding long acting reversible family planning methods and training should also be provided for community health workers. Further, context based implementation research should be required to design more effective methods of family planning information for women as well as their sexual mates.

\footnotetext{
Abbreviations

LARCs: Long acting reversible contraceptives; LAFP: Long acting family planning; WURTH: Wachemo University Referral Teaching Hospital; MDGs: Millennium development goals; IUCD: Intrauterine contraceptive device; EDHS: Ethiopian Demographic Health Survey; PH: Primary Hospital; HSTP: Health sector transformation plan.
}

\section{Supplementary Information}

The online version contains supplementary material available at https://doi. org/10.1186/s12978-022-01357-2.

Additional file 1. Checklist for magnitude and factors for discontinuation and switching off long acting reversible contraceptive users in Hadiya Zone, Ethiopia, 2019.

\section{Acknowledgements}

We would like to thank Hossana College of Health Sciences Research and publication for approving the ethical methodological procedures through the research and ethical technical review committee and funding this research activity. We would also like to acknowledge the officials and concerned staffs in the selected health facilities for providing relevant information and cooperation; data collectors for collecting the required information.

\section{Authors' contributions}

$\mathrm{TB}, \mathrm{YH}$ and $\mathrm{BA}$ conceived the idea, wrote the proposal, participated in data management, analysed the data and drafted the paper. ME and MA approved the proposal, participated in data analysis and revised subsequent draft of the paper. All authors read and approved the final manuscript.

\section{Funding}

This work was supported by the Hossana College of Health Sciences with a Grant number: HCS-6223. The funder has no role on preparing methodological and analytical procedures followed in the research procedure other than check-ups and reviews periodically as per the schedule.

\section{Availability of data and materials}

All data are available within the manuscript. The datasets used and/or analysed during the current study are available from the corresponding author based on reasonable request.

\section{Declarations}

Ethics approval and consent to participate

Ethical clearance from the ethics committee of Hossana College of Health Sciences was obtained. Permission was obtained from all included healthcare facilities though a permission request letter written by the research and community service directorate of the college. The head of the each healthcare facility was provided detailed information about the purpose of the study and consent was obtained accordingly. Client's key identifiers like name were not recorded on the checklist.

\section{Consent for publication}

Not applicable.

\section{Competing interests}

The authors declare that they have no competing interests.

\section{Author details}

${ }^{1}$ Department of Midwifery, Hossana College of Health Sciences, P.O. Box: 159, Hossana, Ethiopia. ${ }^{2}$ Department of Public Health, Hossana College of Health Science, Hossana, Ethiopia. ${ }^{3}$ Department of Health Extension Services, Hossana College of Health Sciences, Hossana, Ethiopia. ${ }^{4}$ Department of Clinical Nurses, Hossana College of Health Sciences, Hossana, Ethiopia. ${ }^{5}$ Department of Midwifery, Hossana College of Health Sciences, Hossana, Ethiopia. ${ }^{6}$ Present Address: College of Health Sciences, School of Public Health, Addis Ababa University, Addis Ababa, Ethiopia.

Received: 16 September 2021 Accepted: 26 January 2022

Published online: 19 February 2022

\section{References}

1. Cleland J, Conde-Agudelo A, Peterson H, Ross J, Tsui A. Contraception and health. The Lancet. 2012;380(9837):149-56.

2. WHO. Maternal Mortality. Fact Sheet. 19 September 2019. Available at: https://www.who.int/news-room/fact-sheets/detail/maternal-mortality Accessed on 25 August 2019.

3. Jacob R, Bakamjian L, Pile M. Threatened and still greatly needed Family planning programs in Sub-Saharan Africa. 2008, New York: The ACQUIRE Project/Engender Health, Advocacy Brief No. 2.

4. United Nations, Department of Economic and Social Affairs, Population Division. Contraceptive Use by Method 2019: Data Booklet (ST/ESA SER.A/435). Available from:https://www.un.org/development/desa/pd/ sites/www.un.org.development.desa.pd/files/files/documents/2020/Jan/ un_2019_contraceptiveusebymethod_databooklet.pdf. Accessed on:25 Jan 2019.

5. USAID. Addressing unmet need for family planning in Africa: the case for long-acting and permanent methods. Pan Afr Med J. 2005.

6. Abajobir AA. Intention to use long-acting and permanent family planning methods among married 15-49 years women in Debremarkos Town, Northwest Ethiopia. Family Med Med Sci Res. 2014, 6(8). 
7. Dida N, Darega B, Takele A. Reproductive health services utilization and its associated factors among Madawalabu University students, Southeast Ethiopia: cross-sectional study. BMC Res Notes. 2015;8:8.

8. Fekadu H, Yesuf KA, Hussien EA, Tafa GM. Prevalence and determinant factors of long acting contraceptive utilization among married women of reproductive age in Adaba Town, West Arsi Zone, Oromia, Ethiopia. J Women's Health Care. 2017;6:360. https://doi.org/10.4172/2167-0420. 1000360).

9. FMOH. Health Sector Transformation plan 2016 to 2020. Addis Ababa, Ethiopia.

10. Joshi R, Khadilkar S, Patel M. Global trends in use of long-acting reversible and permanent methods of contraception: seeking a balance. Int J Gynecol Obstet. 2015;131:S60-3.

11. Luchetti $G$, Romero M. Regional survey on determinants for offering and inserting intrauterine devices carried out among health care providers. Rev Argent Public Health Care. 2017;8:8-12.

12. Jaccard J. Unlocking the contraceptive conundrum unplanned pregnancy. Washington, DC. 2009.

13. Atnafe M, Assefa N, Alemayehu T. Long-acting family planning method switching among revisit clients of public health facilities in Dire Dawa, Ethiopia. BMC Contracept Reprod Method. 2016;1:18.

14. Federal Democratic Republic of Ethiopia, Ethiopia Demographic and Health Survey 2016, Central Statistical Agency, Addis Ababa, Ethiopia.

15. Zenebe CB, Adefris M, Yenit MK, Gelaw YA. Factors associated with utilization of long-acting and permanent contraceptive methods among women who have decided not to have more children in Gondar city. BMC Women's Health. 2017;17:75. https://doi.org/10.1186/ s12905-017-0432-9.

16. Lawrence B. Use of highly effective contraceptive methods increases substantially, but remains low among women at highest risk of unplanned pregnancy. Guttmacher Institute July 2012.

17. Jacqueline $\mathrm{C}$. The rising proportion of repeat teenage pregnancies in young women presenting for termination of pregnancy from 1991 to 2007. Contraception. 2009;79(5):393-6.

18. Hadiya Zone Health Bureau. Annual Health Sector Performance Report of 2018. Hadiya Zone, Hossana, Southern Ethiopia. 2019. [Unpublished].

19. Janine BO, Llene S. What differentiates method stoppers from switchers? Contraceptive discontinuation \& switching among Honduran women. Int Perspect Sex Reprod Health. 2011;37(1):16-23.

20. Ontiri S, Were V, Kabue M, Biesma-Blanko R, Stekelenburg J. Patterns \& determinants of modern contraceptive discontinuation among women of reproductive age: analysis of Kenya Demographic Health Surveys, 2003-2014. PLoS ONE. 2020;15(11):e0241605.

21. Burusie A. Reasons for premature removal of implanon among users in Arsi Zone, Oromia Region, Ethiopia. Reprod Syst Sex Disord. 2015;4(1):1-6.

22. Fekadu GA, Omigbodun AO, Roberts OA, Yalew AW. Factors associated with early long-acting reversible contraceptives discontinuation in Ethiopia: evidence from the 2016 Ethiopian demographic and health survey. Arch Public Health. 2020;78:36.

23. Lakha F, Glasier AF. Continuation rates of implanon in the UK: data from an observational study in Clinical settings. Contraception. 2006;74(287):289.

24. Ali MM, Park MH, Ngo TD. Levels and determinants of switching following intrauterine device discontinuation in 14 developing countries. Contraception. 2014;90:47-53.

25. Kelborea W, Yesuf N, Alto G. Long acting reversible contraceptive methods switching and associated factors among women attending family planning clinic at public health facilities of Dilla Town, Southern Ethiopia. Int J Sci Basic Appl Res (IJSBAR). 2020;53(2):59-72.

26. Barden-O'Fallon J, Speizer IS, Calhoun LM, Corroon M. Women's contraceptive discontinuation and switching behavior in urban Senegal, 2010-2015. BMC Women's Health. 2018;18:35.

27. Mrwebi KP, Goon DT, Owolabi EO, Adeniyi OV, Seekoe E, Ajayi Al. Reasons for discontinuation of implanon among users in Buffalo city metropolitan municipality, South Africa: a cross-sectional study. Afr J Reprod Health. 2018:22(1):113.

28. Haddad L, Wall KM, Vwalika B, Khu NH. Contraceptive discontinuation and switching among couples receiving integrated HIV and family planning services in Lusaka, Zambia. Europe PMC plus, 2014.
29. Izugbara CO, Wekesah FM, Tilahun T, Amo-Adjei J, Tsala DT. Family planning in East Africa: Trends and Dynamics. African Population and Health Research Center (APHRC), Nirobi, Kenya; 2018.

\section{Publisher's Note}

Springer Nature remains neutral with regard to jurisdictional claims in published maps and institutional affiliations.
Ready to submit your research? Choose BMC and benefit from:

- fast, convenient online submission

- thorough peer review by experienced researchers in your field

- rapid publication on acceptance

- support for research data, including large and complex data types

- gold Open Access which fosters wider collaboration and increased citations

- maximum visibility for your research: over $100 \mathrm{M}$ website views per year

At BMC, research is always in progress.

Learn more biomedcentral.com/submissions 